\title{
Helmut Kreuzer
}

\author{
Einleitung
}

Hätte Alfred Nobel (1833-1896) nicht die Nobelpreise gestiftet, wäre er in Fachkreisen als Erfinder des Dynamits und anderer Sprengstoffe noch bekannt. Er stünde auch noch im Großen Brockhaus; aber er wäre heute schwerlich im Bewußtsein einer breiteren Öffentlichkeit so präsent wie der Preisstifter Nobel. Mit dessen Namen sind mehr Gebildete in aller Welt vertraut als mit dem Namen irgendeines Marschalls, Königs oder Kaisers seit der napoleonischen Ära. Als die LiLi-Herausgeber sich für ein Themenheft zum Literaturnobelpreis entschieden, waren gerade hundert Jahre seit dem Tod Nobels verstrichen. 1895 wurde die entscheidende Fassung des Testaments verfaßt, 1901 wurde der erste Literaturnobelpreis verliehen. Der Preis ist heute international so bekannt, begehrt und umstritten wie kein anderer Literaturpreis. Die Nobelpreise für Wissenschaftler genießen in deren Fächern hohes Ansehen. Zwar gingen Nobelpreise - nach der Meinung von Fachleuten - nicht an alle, die ihrer würdig gewesen wären (ein Beispiel ist Lise Meitner); aber so gut wie alle, die sie erhielten, verdienten sie auch - wiederum nach Meinung von Fachleuten, denen die Preisträger gewöhnlich schon vor der Preisverleihung als Meister in ihrem Fach bekannt waren, während eine breitere Öffentlichkeit die Namen vieler von ihnen schon wieder vergessen hat. Die Grundlagenforschung wird besonders gerne ausgezeichnet, obwohl die Intention des Stifters wohl eher dahin ging, Forschungen mit besonders hohem Nutzwert zu belohnen. Der Friedensnobelpreis wird zwar stark beachtet; aber die meisten seiner Träger wurden durch den Preis nicht bekannter, als sie ohnehin schon waren, und sie bilden ein sehr inhomogenes Ensemble: von Arafat und Begin bis zu Rabin und Sadat bzw. bis zu Albert Schweitzer und der Schriftstellerin Bertha von Suttner; nicht wenige unter ihnen haben sich nicht erst mit Verdiensten um den Frieden ins Buch der Geschichte eingeschrieben, sondern schon zuvor mit ihren Verdiensten um die militärische Rüstung und den Sieg in Kriegen, die viele Menschenleben forderten. (Und der Frieden im Nahen Osten ist nach Rabins Ermordung wieder weit in die Ferne gerückt.)

Die Verleihung des Nobelpreises für Literatur stößt auf das Interesse von Autoren und ihren Übersetzern, Verlegern, Buchhändlern, Literaturredaktionen, ja von Millionen interessierter Leser. Wer im literarischen Leben irgendwie mitspielt (oder wer auch nur einen >Kultautor< ohne Nobelpreis für sich entdeckt hat), der hat in vielen Fällen auch schon seinen eigenen Kandidaten im Hinterkopf, so daß bei ihm Enttäuschung und Überraschung sich mischen, wenn ein Dritter den Preis bekommt. Dieser ist von eminenter rezeptionsge- 
schichtlicher Bedeutung, ganz unabhängig davon, ob die getroffene Wahl auf Zustimmung bei einem geläufigen Namen trifft, auf Neugier bei einem für viele neuen Namen, auf Kritik, ja auf Hohn bei einer >Fehlentscheidung <, die an den Maßstäben der zeitgenössischen Kritik vorbeigeht. Nicht nur Fachleute (wie bei den Wissenschaftspreisen) trauen sich hier ein eigenes Urteil zu; und die Urteile der Vielen hängen vom subjektiven Geschmack wie von ganz unterschiedlichen literarischen Kenntnissen und außerliterarischen Präferenzen ab, von Kenntnissen und Meinungen in bezug auf Sprachen, Völker, Länder und Kulturen, auf literarische Gattungen und biologische Geschlechter.

Wolfgang Klein geht in seinem einleitenden Essay auf das Vermächtnis des Stifters ein: dessen Willen, daß nicht speziell das zeitgenössische Meisterwerk als solches zu finden und auszuzeichnen sei, sondern das vorzüglichste unter den jeweils neuen (oder erst neuerdings in ihrem Wert erkannten) Literaturwerken idealischer Prägung. Er wollte nur solche literarischen Werke fördern, die der Menschheit auf ihrem geistig-sittlichen Entwicklungsweg weiterhelfen können. So ergaben sich sonderbare Kompromisse, wenn die ästhetischen, humanitären, utilitaristischen Kriterien der in den ersten Jahrzehnten meist konservativen Juroren sich mit ihren Interpretationen des Nobelschen »Idealismus « nicht zur Deckung bringen ließen. (Daß auch politische Affinitäten eine Rolle spielten, versteht sich im zwanzigsten Jahrhundert von selbst.) Immer stärker aber habe sich - so Klein - eine Interpretation des Testamentes durchgesetzt, die ihrerseits »idealistische « Züge trägt und daraus ihren Anspruch begründet, im Sinne Nobels zu handeln und doch nicht nach seinen Worten zu verfahren: »Es soll nicht der schnöde Nutzen geehrt werden, für die vielen, die leiden und die sich freuen, sondern etwas viel Edleres - das Streben nach künstlerischer Vollendung und nach reiner Erkenntnis. Es ist dies eigentlich die Perversion dessen, was Nobel mit idealisch meinte, und es ist mehr als eigen, daß sich diese Vorstellung am Ende unseres Jahrhunderts so fraglos durchgesetzt hat.«

Christoph König hat einen originellen Ansatz für sich gefunden: Er fragt nicht nach den Preisträgern aus der deutschen Literatur, sondern nach denen, die vorgeschlagen, aber übergangen wurden; er umreißt die Kriterien heutiger Mitglieder der Schwedischen Akademie, die den Preis vergibt, und wägt die gesunkenen Chancen deutscher Autoren ab, künftig den Preis zu gewinnen. Der Skandinavist Walter Baumgartner gewährt am Beispiel des Preisträgers Knut Hamsun kritisch-desillusionierende Einblicke in die Motive, Kriterien und Argumentationsmuster der beteiligten Akademie- und Preiskomitee-Mitglieder und relativiert dergestalt »die damalige Kompetenz der schwedischen Akademie als weltliterarischer Richtungsinstanz.«Wolfgang Kasack läßt die russischen Nobelpreisträger Revue passieren und begründet - mit punktuellem Vorbehalt - sein Einverständnis mit den getroffenen (auch politisch relevanten) Wahlen. Cathy Waegner wendet sich den amerikanischen Nobelpreisträgern zu und konzentriert sich auf eine Preisträgerin: Toni Morrison (auch in ihrer relativen Nähe zu Faulkner). Pamela Z. Dube beschreibt die 
Ambivalenzen, die sich mit dem Ausgriff der Jury auf afrikanische Autoren (Wole Soyinka, Nadine Gordimer) verbinden.

Zusammenfassend läßt sich wohl sagen, daß bisher hauptsächlich die Literaturen Europas und der amerikanischen Kontinente ins Blickfeld geraten sind, daß die Prosa-Erzähler auffällig dominieren und daß die schreibenden Frauen noch nicht adäquat repräsentiert sind. Doch davon sollte sich kein LiLi-Leser (die Literaturprofessoren unter ihnen sind vorschlagsberechtigt) mit europäischem Urteilsradius abhalten lassen, weitere preiswürdige europäische Prosa-Erzähler beider Geschlechter vorzuschlagen, und es anderen LiLi-Lesern - mit einer anderen Reichweite ihrer Kenntnisse - überlassen, Lyriker(innen), Dramatiker(innen), Autor(inn)en nichtfiktionaler Texte bzw. Schreibende aus anderen Kulturregionen und Sprachräumen mit ins Spiel zu bringen. 